\title{
Awareness and use of cardiovascular risk scores by family physicians in southeastern Ontario*
}

\author{
Murray F. Matangi ${ }^{1 \#}$, David W. J. Armstrong ${ }^{1}$, Amer M. Johri ${ }^{2}$, Ursula Jurt ${ }^{1}$, Peter M. Hollett ${ }^{3}$, \\ Robert W. Del Grande ${ }^{4}$, J. Paul DeYoung ${ }^{5}$, Joel M. Niznick ${ }^{6}$, Daniel D. Broiullard ${ }^{1}$ \\ ${ }^{1}$ The Kingston Heart Clinic, Kingston, Canada; ${ }^{\#}$ Corresponding Author: murraymatangi@hotmail.com \\ ${ }^{2}$ Division of Cardiology, Kingston General Hospital and Queen's University, Kingston, Canada \\ ${ }^{3}$ Belleville General Hospital, Belleville, Canada \\ ${ }^{4}$ Perth \& Smiths Falls District Hospital, Perth, Canada \\ ${ }^{5}$ Cornwall General Hospital, Cornwall, Canada \\ ${ }^{6}$ Ottawa Cardiovascular Centre, Ottawa, Canada
}

Received 11 September 2013; revised 14 October 2013; accepted 26 October 2013

Copyright (C) 2013 Murray F. Matangi et al. This is an open access article distributed under the Creative Commons Attribution License, which permits unrestricted use, distribution, and reproduction in any medium, provided the original work is properly cited.

\begin{abstract}
Background: Our objective was to determine the assessment of cardiovascular risk by family physicians. Methods: A questionnaire was sent by mail or fax regarding both awareness and use of the various CV risk scores in southeastern Ontario. Results: Of $\mathbf{1 8 1}$ family physicians surveyed, $96 \%$ were aware of at least one CV risk score and $40 \%$ were aware of the JUPITER study. Despite this awareness, $72 \%$ simply counted risk factors to assess risk, rather than to calculate risk using established scoring methods. Only $23 \%$ used the JUPITER study criteria. This suggests an under-estimated of overall CV risk by family physician's practicing in southeastern Ontario. Interpetation: Cardiovascular risk in primary care is being underestimated in southeastern Ontario. Additional knowledge translation strategies are required to enhance the family physician's awareness and use of established risk scoring methods if we are to reduce the burden of CV disease.
\end{abstract}

Keywords: Risk Assessment; Primary Prevention; Cardiovascular Disease

\section{INTRODUCTION}

Cardiovascular (CV) risk stratification using a method such as the Framingham risk score (FRS) for total CV events is recommended in the 2012 Canadian lipid guidelines [1]. Gupta and colleagues have recently pub-

\footnotetext{
*Funding sources: none; Disclosures: none.
}

lished data indicating that two-thirds of motivated Canadian family physicians calculate the FRS [2]. They also indicated that there were substantial gaps in knowledge regarding the implementation of the FRS with respect to modification of the risk by family history and clinical scenarios that warrant hsCRP measurement, a marker of inflammation [2]. Gupta and colleagues have stated their results indicating a "best case scenario" as the physicians selected from the 105 clinical sites across Canada chosen for their expertise and heightened awareness of the $\mathrm{Ca}$ nadian lipid guidelines [2]. We feel it unlikely that this best case scenario translates into routine family practice.

The purpose of our study was to conduct a survey of family physicians to assess the awareness and use of the various $\mathrm{CV}$ risk scores.

\section{METHODS}

A group of community $\mathrm{CV}$ specialists and general internists conducted a survey of their referring family physicians in southeastern Ontario. The survey (Table 1) was sent by facsimile (FAX) or letter to the family physicians' office. All completed surveys were returned by FAX to our facility, where the data were collected and analyzed. We asked two simple series of questions: the first was to assess whether the physician was aware of the various $\mathrm{CV}$ risk scores and the second question was what method(s) the physician used in day-to-day practice to assess $\mathrm{CV}$ risk. The questionnaire was anonymous and it was stressed to participating family physicians that they should indicate what they actually do in daily practice, as opposed to what they think they should be doing. The questionnaire was on a single sheet of pape (Table 1). HEART Score [3], a European CV risk assessment 
Table 1. Cardiovascular awareness and use questionnaire.

\begin{tabular}{|c|c|c|}
\hline Vascular risk scoring systems that I know & Yes & No \\
\hline \multicolumn{3}{|l|}{ Framingham risk score for global events } \\
\hline \multicolumn{3}{|l|}{ Framingham risk score for coronary events } \\
\hline \multicolumn{3}{|l|}{ Reynolds risk score } \\
\hline \multicolumn{3}{|l|}{ Heart score } \\
\hline \multicolumn{3}{|l|}{ JUPITER study criteria } \\
\hline \multicolumn{3}{|l|}{$\begin{array}{l}\text { ARIC risk score with carotid imaging } \\
\text { for coronary events }\end{array}$} \\
\hline I use the following on eligible patients & Yes & No \\
\hline \multicolumn{3}{|l|}{ Framingham risk score for global events } \\
\hline \multicolumn{3}{|l|}{ Framingham risk score for coronary events } \\
\hline \multicolumn{3}{|l|}{ Reynolds risk score } \\
\hline \multicolumn{3}{|l|}{ Heart score } \\
\hline \multicolumn{3}{|l|}{ JUPITER study criteria } \\
\hline \multicolumn{3}{|l|}{$\begin{array}{l}\text { ARIC risk score with carotid imaging for } \\
\text { coronary events }\end{array}$} \\
\hline I count vascular risk factors to determine Statin $\mathrm{Rx}$ & & \\
\hline $\begin{array}{l}\text { I do not use any risk scoring system to } \\
\text { determine the need for Statin Rx }\end{array}$ & & \\
\hline
\end{tabular}

Note: This survey is anonymous so please indicate what you actually do and not what you think you should be doing.

tool was added as a "control". Most Canadian physicians would not be familiar with this CV risk assessment tool. Therefore an affirmative response rate to the awareness and use of HEART Score was expected to be very low.

A considerable percentage of FPs stated they counted vascular risks scores instead of using a conventional risk score. We therefore calculated the diagnostic accuracy of counting vascular risk factors (age, family history, smoking, diabetes). In CARDIOfile ${ }^{\mathrm{TM}}$, our comprehensive cardiology database, we selected males $\geq 40$ and females with $\geq 50$ with no history of vascular disease and not taking a statin ( $\mathrm{N}=1465$ consecutive patients). There were 647 patients who met these criteria and had their FRS calculated: 292 females, mean age $65.1 \pm 9.9$, LDL cholesterol $3.21 \pm 0.97$, HDL cholesterol $1.60 \pm 0.42$; $13.5 \%$ had diabetes, $8.2 \%$ were current smokers, $15.8 \%$ had a family history of premature coronary disease. The mean FRS for total CV events for females was $13.7 \pm 8.4$ There were 355 males, mean age $60.3 \pm 12.0$, LDL cholesterol $3.05 \pm 0.91$, HDL cholesterol $1.42 \pm 0.42 ; 10.7 \%$ had diabetes, $20.3 \%$ were current smokers, $18.9 \%$ had a family history of premature coronary disease. The mean FRS for total CV events for males was $22.1 \pm 10.0$.

\section{RESULTS}

One hundred and eighteen family physicians out of
$231(51.1 \%)$ contacted by FAX returned the survey by FAX compared to only 63 of $500(12.6 \%)$ who were contacted by letter giving an overall response of 181 of $731(24.8 \%)$.

Ninety-six percent of family physicians were aware of at least one of the various CV risk scores (mostly FRS); $44 \%$ were aware of the Reynolds risk score, and $40 \%$ were aware of the JUPITER trial [4]. Only 5\% had awareness of the ARIC (Atherosclerosis risk in communities) risk score 5 which utilizes carotid ultrasound (Figure 1, solid bars). As expected, the response rate to the HEART score (1\%) was very low. Sixty-six percent were aware that the current FRS was a global risk score, and 30\% thought the currently recommended FRS was still a coronary risk score. Despite this awareness of CV risk scores, $72 \%$ of family physicians stated they count risk factors to assess CV risk and the need for statin therapy. Only $23 \%$ of those questioned used the JUPITER study criteria for hsCRP (Figure 1, hatched bars).

Our cardiology database was used to determine the accuracy of counting vascular risk factors to identify high-risk patients, using the FRS for total CV events as the gold standard (Table 2). The sensitivity and specificity of counting vascular risk factors were relatively poor, suggesting that counting vascular risk scores underestimates $\mathrm{CV}$ risk in high risk patients and overestimates $\mathrm{CV}$ risk in low and intermediate risk patients. Various risk factor profiles demonstrate that simply counting risk factors is a poor method of stratifying vascular risk (Table 3).

\section{INTERPRETATION}

Our survey indicated that while $96 \%$ of family physicians are aware of at least one of the many CV risk scores, $72 \%$ often simply counted vascular risk factors to assess CV risk. Counting vascular risk factors is quick and is likely preferred because of the short time allotted for each patient interview. Counting vascular risk factors has a poor accuracy for detecting high-risk patients, as many eligible patients will be excluded from therapeutic



-Risk scorelRisk score use

Figure 1. Family physician cardiovascular risk score awareness and use. 
Table 2. The accuracy of counting vascular risk scores for the detection of high risk patients according to Framingham risk score for total CV events.

\begin{tabular}{ccccc}
\hline & $\begin{array}{c}\text { Sensitivity, } \\
\%[95 \% \mathrm{CI}]\end{array}$ & $\begin{array}{c}\text { Specificity, } \\
\%[95 \% \mathrm{CI}]\end{array}$ & $\begin{array}{c}\text { Positive Predictive Value, } \\
\%[95 \% \mathrm{CI}]\end{array}$ & $\begin{array}{c}\text { Negative Predictive Value, } \\
\%[95 \% \mathrm{CI}]\end{array}$ \\
\hline Males & $74.6[67.9-80.3]$ & $82.5[75.4-87.9]$ & $49.9[44.5-55.1]$ & $50.1[44.8-55.4]$ \\
Females & $78.3[66.4-86.9]$ & $51.1[44.4-57.8]$ & $55.8[49.9-61.6]$ & $44.2[38.4-50.1]$ \\
\hline
\end{tabular}

Table 3. The proportion of patients with various risk factor profiles that have low, intermediate or high Framingham Risk Score for total cardiovascular events. These data demonstrate that simply counting risk factors is a poor method for stratifying vascular risk. $\mathrm{FH}=$ family history.

\begin{tabular}{|c|c|c|c|}
\hline \multicolumn{4}{|c|}{ Male } \\
\hline RISK FACTORS (N) & LOW RISK, N (\%) & INTERMEDIATE RISK, N (\%) & HIGH RISK, N (\%) \\
\hline Age $50-69$ yrs + FH (28) & $3(10.7)$ & $8(28.6)$ & $17(60.7)$ \\
\hline Age $50-69$ yrs + Smoking (22) & $1(5.0)$ & $5(22.7)$ & $16(72.7)$ \\
\hline Age $50-69 \mathrm{yrs}+\mathrm{FH}+$ smoking (11) & $1(9.0)$ & $3(27.2)$ & $7(63.6)$ \\
\hline Age $50-69$ yrs and diabetic (25) & $0(0.0)$ & $0(0.0)$ & $25(100)$ \\
\hline Males $>69$ years $(91)$ & $0(0.0)$ & $6(6.6)$ & $85(93.1)$ \\
\hline \multicolumn{4}{|c|}{ Females } \\
\hline RISK FACTORS (N) & LOW RISK, N (\%) & INTERMEDIATE RISK, N (\%) & HIGH RISK, N (\%) \\
\hline Age $50-69$ yrs + FH (28) & $15(53.6)$ & $13(46.8)$ & $0(0.0)$ \\
\hline Age $50-69$ yrs + Smoking (19) & $6(31.6)$ & $8(42.1)$ & $5(26.3)$ \\
\hline Age $50-69$ yrs + FH + smoking (9) & $3(33.3)$ & $1(11.1)$ & $5(55.6)$ \\
\hline Age $50-69$ yrs and diabetic (14) & $3(21.4)$ & $5(35.7)$ & $6(42.9)$ \\
\hline Males $>69$ years $(93)$ & $24(25.8)$ & $31(33.3)$ & $38(40.8)$ \\
\hline
\end{tabular}

intervention. Interestingly, the sensitivity and specificity of counting risk factors was lower in women compared to men, and there is evidence that vascular risk remains underestimated in women $[5,6]$.

There is definite confusion regarding the current recommended version of the FRS, which is for total CV events. We have published data indicating that simply changing from the coronary version of the FRS to the global version more than doubles the number of patients who qualify for lipid lowering therapy [7]. Our current survey indicated that $30 \%$ were aware of only the coronary version of the FRS. However, it is important to note that family physicians calculating the FRS for total CV events may be unaware that it is for global CV risk stratification.

The awareness and utilization of hsCRP were low. Only $40 \%$ of family physicians were aware of the JUPITER trial and only $23 \%$ indicated they use this study in the risk assessment of their patients. Most JUPITER patients appear to be low or intermediate risk simply because their LDL-cholesterol is "normal" $(<3.40$ $\mathrm{mmol} / \mathrm{L})$. However, if one does not measure hsCRP then one cannot detect these high-risk patients with a normal LDL-cholesterol. Although the JUPITER trial 4 has received widespread attention, it has been reported that only half of family physicians view inflammation as important in the progression of atherosclerosis, and that there is a significant knowledge and implementation deficit when it comes to this important method of assessing CV risk [2].

It is important to also consider data challenging the tenets of the FRS as the gold standard of CV risk stratification. For instance, half of patients that suffer a myocardial infarction have normal LDL cholesterol levels [8]. Furthermore, based on current guidelines $75 \%$ of patients do not qualify for statin therapy prior to suffering their first myocardial infarction [8]. Clearly, more accurate methods of risk assessment are essential, but it is equally imperative that the use of emerging tools be translated into clinical practice. Frankly, a useful tool, unused, is useless.

Given the knowledge deficits identified, we believe as cardiologists and educators a better job can be done to enhance the family physician's awareness and under- 
standing of CV risk assessment. Additionally, we believe simple technology should play an important role in the assessment and implementation of CV risk in primary care. The use of electronic medical records (EMR) has been increasing in Ontario [9], and an electronic version of the CV risk assessment should be an integral part of any EMR. This would permit a streamlined and standardized method of efficiently identifying patients whose quality for risk assessment, as well as any necessary blood work and imaging may be required for a complete risk assessment.

\section{STUDY LIMITATIONS}

Our survey was an awareness and use survey, and we did not assess either the knowledge or ability to implement the various $\mathrm{CV}$ risk scores.

The overall response rate to our survey was low (25\%). The response rate to FAX alone was excellent at 51\%. The letter response rate was very low at $13 \%$. We believe that the family physicians who responded represent the motivated and are more likely to be committed to $\mathrm{CV}$ risk assessment than those who did not respond.

\section{CONCLUSION}

Cardiovascular risk assessment in primary care in southeastern Ontario is clearly being under-estimated. If we are to reduce the burden of $\mathrm{CV}$ disease additional strategies which are required. One strategy should involve in a more active role of the EMR and the use of email to alerting the family physician. Such a strategy would lead to a more extensive use of evidenced based lipid management.

\section{ACKNOWLEDGEMENTS}

The authors thank the physicians who responded to the questionnaire.

\section{REFERENCES}

[1] Anderson, T.J., Grégoire, J., Hegele, R.A., Couture, P., Mancini, G.B., McPherson, R., Francis, G.A., Poirier, P., Lau, D.C., Grover, S., Genest, J., Jr., Carpentier, A.C., Dufour, R., Gupta, M., Ward, R., Leiter, L.A., Lonn, E., Ng, D.S., Pearson, G.J., Yates, G.M., Stone, J.A. and Ur, E. (2013) 2012 Update of the Canadian Cardiovascular Society guidelines for the diagnosis and treatment of dyslipidemia for the prevention of cardiovascular disease in the adult. Canadian Journal of Cardiology, 29, 151157. http://dx.doi.org/10.1016/j.cjca.2012.11.032

[2] Gupta, M., Singh, N., Tsigoulis, M., Kajil, M., Hirjikaka, S., Quan, A., Teoh, H. and Verma, S. (2012) Perceptions of Canadian Primary care physicians towards cardiovascular risk assessment and lipid management. Canadian Journal of Cardiology, 28, 14-19. http://dx.doi.org/10.1016/j.cjca.2011.09.014

[3] Conroy, R.M., Pyörälä, K., Fitzgerald, A.P., Sans, S., Menotti, A., De Backer, G., De Bacquer, D., Ducimetière, P., Jousilahti, P., Keil, U., Njølstad, I., Oganov, R.G., Thomsen, T., Tunstall-Pedoe, H., Tverdal, A., Wedel, H., Whincup, P., Wilhelmsen, L. and Graham, I.M. (2003) Estimation of ten-year risk of fatal cardiovascular disease in Europe: the SCORE project. European Heart Journal, 24, 987-1003.

http://dx.doi.org/10.1016/S0195-668X(03)00114-3

[4] Ridker, P.M., Danielson, E., Fonseca, F.A., Genest, J., Gotto, A.M., Jr., Kastelein, J.J., Koenig, W., Libby, P., Lorenzatti, A.J., MacFadyen, J.G., Nordestgaard, B.G., Shepherd, J., Willerson, J.T. and Glynn, R.J. (2008) Rosuvastatin to prevent vascular events in men and women with elevated C-reactive protein. The New England Journal of Medicine, 359, 2195. http://dx.doi.org/10.1056/NEJMoa0807646

[5] Mosca, L., Barrett-Connor, E. and Wenger, N.K. (2011) Sex/Gender differences in cardiovascular disease prevention what a difference a decade makes. Circulation, 124, 2145-2154.

http://dx.doi.org/10.1161/CIRCULATIONAHA.110.9687 $\underline{92}$

[6] Linton, M.R.F. and Fazio, S. (2003) A practical approach to risk assessment to prevent coronary artery disease and its complications. American Journal of Cardiology, 92, 19-26. http://dx.doi.org/10.1016/S0002-9149(03)00505-8

[7] Armstrong, D.W.J., Brouillard, D. and Matangi, M.F. (2011) The effect of the change in the Framingham risk score calculator between the 2006 and 2009 Canadian lipid guidelines. Canadian Journal of Cardiology, 27, 167-170. http://dx.doi.org/10.1016/j.cjca.2010.12.025

[8] Sachdeva, A., Cannon, C.P., Deedwania, P.C., Labresh, K.A., Smith, S.C., Jr., Dai, D., Hernandez, A. and Fonarow, G.C. (2009) Lipid levels in patients hospitalized with coronary artery disease: An analysis of 136,905 hospitalizations in Get With The Guidelines. American Heart Journal, 157, 111-117.

http://dx.doi.org/10.1016/j.ahj.2008.08.010

[9] Biro, S.C., Barber, D.T. and Kotecha, J.A. (2012) Trends in the use of electronic medical records. Canadian Family Physician, 58, e21. 